\title{
Políticas públicas para a educação superior: a avaliação, a regulação e a supervisão de IES privadas em debate
}

\author{
Annor da Silva Junior* \\ Caio Eduardo de Guido Polizel** \\ Simone de Souza*** \\ Alfredo Rodrigues Leite da Silva**** \\ Priscilla de Oliveira Martins da Silva***** \\ Susane Petinelli Souza ${ }^{\star \star \star \star \star *}$
}

\section{Resumo}

Objetivou-se evidenciar e discutir as articulações das Instituições de Educação Superior (IES) privadas em torno de três aspectos relacionados às políticas públicas para a educação superior: avaliação, regulação e supervisão. A discussão fundamenta-se em dados coletados e analisados por meio de cinco estudos de casos. Os resultados indicam a necessidade de se repensar as políticas públicas, sobretudo em termos dos efeitos práticos da regulamentação governamental nas IES e das definições dos papéis e funções desses três aspectos. Essas políticas públicas interferem na gestão universitária, sem, contudo, avaliar a sua efetividade prática, fazendo com que a dinâmica entre as IES e as políticas públicas assuma uma lógica formalística que acarreta prejuízos para a educação superior e para a sociedade.

Palavras-chave: Gestão Universitária. Políticas Públicas. Educação Superior.

\section{Introdução}

O objetivo deste estudo é evidenciar e discutir as articulações das Instituições de Educação Superior (IES) privadas em torno de três aspectos relacionados às políticas públicas para a educação superior elaboradas pelo governo federal: avaliação, regulação e supervisão (INEP, 2009). Na concepção de suas políticas públicas, o governo federal definiu que a avaliação consiste no referencial básico e norteador para a regulação e a

* Doutor em administração pela UFMG. Professor adjunto da UFES. E-mail: annorsj@gmail.com

** Mestre em administração pela FUCAPE. Consultor educacional. E-mail: caio@hoper.com.br

*** Mestre em administração pela FUCAPE. Professora do IFES. E-mail: simoni@ifes.edu.br

**** Doutor em administração pela UFMG. Professor adjunto da UFES. E-mail: alfredoufes@gmail.com

$\star \star \star \star \star$ Doutora em Psicologia pela UFES. Professora ajunta da UFES. E-mail: priscillaomartins@hotmail.com

****** Doutoranda em Educação pela UFES. Professora assistente da UFES. E-mail: susipetinelli@gmail.com 
supervisão da educação superior (INEP, 2009). A opção de discutir esses três aspectos neste artigo fundamenta-se no fato de que são eles que formam a base sob a qual a regulamentação se materializa na prática. Isso ocorre por meio de ações planejadas e implementadas pelo Ministério da Educação (MEC) e demais órgãos de sua estrutura de governo, tais como o Conselho Nacional de Educação (CNE); a Secretaria de Educação Superior (SESu); o Instituto Nacional de Estudos e Pesquisas Educacionais Anísio Teixeira (INEP); a Fundação Coordenação de Aperfeiçoamento de Pessoal de Nível Superior (CAPES); entre outros (BRASIL, 2007a; 2007b). A Figura 1 a seguir ilustra esse ambiente institucional de políticas públicas.

Figura 1 - Ambiente Institucional de Políticas Públicas para a Educação Superior no Brasil.

\section{Regulamentação Governamental}

(MEC)

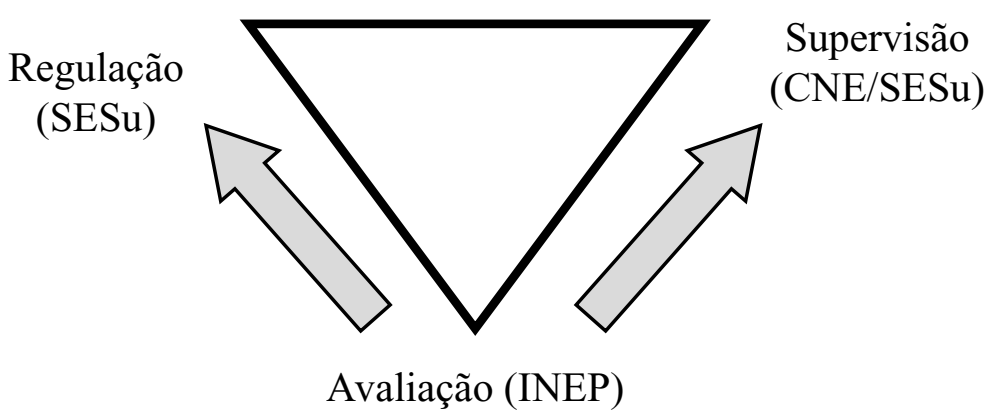

Fonte: INEP (2009) adaptado pelos autores (2014).

$\mathrm{Na}$ atualidade, observa-se o predomínio da educação superior privada no sistema federal, quando comparada com o setor público, representando $89,4 \%$ das IES, $88,6 \%$ do total de vagas ofertadas e $73,6 \%$ do total de matrículas em nível de graduação presencial (INEP, 2011b). Diante dessas constatações, assume-se neste artigo que as políticas públicas para a educação superior em termos de avaliação, regulação e supervisão envolvem predominantemente as IES privadas, razão pelo qual optou-se por esse recorte de pesquisa.

Visando obter coerência analítica entre as distintas formas de organização das IES recorreu-se ao Modelo Estrutural e Dinâmico das IES proposto por Silva Junior e Muniz (2004). O sentido de modelo aqui adotado é o 
de Domingues (2002), ou seja, um instrumento de conhecimento a partir da interpretação da teoria. Assim, os modelos têm por finalidade ajudar a pensar, analisar, decompor, entender e prever a realidade na medida em que permitem manipulá-la (DOMINGUES, 2002). Nessa ótica, o Modelo Estrutural e Dinâmico das IES foi associado à perspectiva do isormofismo institucional de DiMaggio e Powell (1983) para permitir a realização de análise comparativa de casos distintos e a identificação de pontos de convergências e divergências de interpretação das IES pesquisadas, acerca das políticas públicas para a educação superior privada.

Essa abordagem baseou a análise dos dados coletados por meio da realização de estudos de caso qualitativos (YIN, 2005; TRIVIÑOS, 2008) em cinco IES privadas, ao longo de cinco anos. $\mathrm{O}$ foco se voltou para a compreensão de como essas instituições avaliam as políticas públicas do governo federal e como as mesmas interferem na gestão universitária (LAMARRA; BRÁ, 2004; COLOSSI, 2004).

Os dados foram coletados por meio de triangulação (JICK, 1979) na qual se articulou análise documental, observação assistemática e entrevistas semiestruturadas junto a 43 gestores educacionais com atuação nas entidades mantenedora e mantida das cinco IES pesquisadas. Os dados coletados foram submetidos à análise temática do conteúdo (BARDIN, 2004, MINAYO, 2001) que permitiu confrontar as contribuições empíricas com as articulações teóricas construídas ao longo da discussão proposta.

Para organizar a discussão este artigo está estruturado em sete tópicos, além da introdução apresentada neste primeiro tópico. No segundo, no terceiro e no quarto tópicos discute-se o referencial teórico que fundamenta a análise dos dados abordando-se, respectivamente, as políticas públicas para a educação superior, o isomorfismo institucional na dinâmica das IES brasileiras e o formalismo nas políticas públicas e nas práticas de gestão universitária. No quinto tópico tem-se a apresentação da perspectiva metodológica que operacionalizou as pesquisas. No sexto tópico apresenta-se o contexto da gestão universitária nas IES pesquisadas. No sétimo tópico elabora-se uma reflexão acerca das políticas públicas para educação superior, ao articular os temas avaliação, regulação e supervisão. No oitavo e último tópico são apresentadas as considerações finais do estudo. 


\section{As políticas públicas para a educação superior: avaliação, regulação e supervisão}

O sistema federal de educação superior no Brasil é regulamentado pelo governo federal, por meio do Ministério da Educação e demais órgãos da estrutura de governo, a partir dos marcos de regulamentação da avaliação, da regulação e da supervisão, com o primeiro consistindo no referencial básico para os outros dois. Esses três marcos de regulamentação possuem papéis, funções e articuladores próprios: (1) a avaliação é realizada pelo Sistema Nacional de Avaliação da Educação Superior (SINAES) e operacionalizado pelo Instituto Nacional de Estudos e Pesquisas Educacionais Anísio Teixeira (INEP), a qual articula processos múltiplos envolvendo as IES, os cursos de graduação e os discentes, cuja finalidade é promover a melhoria da qualidade da educação superior; (2) a regulação é realizada pela SESu por meio de atos administrativos autorizativos do funcionamento das IES e de seus cursos; e, (3) a supervisão realizada pelo CNE e pela SESu, cuja finalidade é zelar pela conformidade entre a oferta de educação superior no sistema federal e a legislação aplicável (INEP, 2009).

O sistema de avaliação é composto atualmente de três eixos. O primeiro eixo é o desenvolvimento da avaliação das instituições, tendo como principal objetivo a verificação de como as IES são constituídas e busca saber qual é a sua capacidade de atendimento à comunidade acadêmica. Neste item está incluído o desenvolvimento do processo de auto-avaliação que busca, em primeira instância o auto conhecimento, o que favorece a construção de uma cultura da avaliação na instituição, permitindo que as IES se preparem para as diversas avaliações externas a que são submetidas sistematicamente. O segundo eixo se refere à avaliação dos cursos de graduação já autorizados, que está articulado com o processo de regulação, pois seus resultados estão vinculados por Lei ao reconhecimento e à renovação do reconhecimento dos cursos. $\mathrm{O}$ terceiro eixo avalia o desempenho dos alunos por meio do Exame Nacional de Desempenho dos Estudantes (ENADE), com foco nos conteúdos básicos e profissionalizantes (POLIDORI; MARINHO-ARAÚJO; BARREYRO, 2006).

Segundo o Ministério da Educação, a abordagem adotada atualmente busca um deslocamento da ênfase no desempenho dos alunos (antigo "Provão") para a ênfase no desempenho institucional integrado, para oferecer um contexto propício ao desenvolvimento institucional. Entretanto, o processo avaliativo parece estar 
mais no âmbito da fiscalização de minúcias burocráticas do que do efetivo aprimoramento da educação, envolvendo o ensino, a pesquisa e a extensão, pois ignora especificidades que deveriam ser consideradas.

O aparato regulatório, de acordo com Nunes (2007), não distingue explicitamente entre instituições públicas e privadas, portanto, formalmente, elas são consideradas idênticas. Mas, de fato, não o são, uma vez que as condições, as lógicas e dinâmicas vivenciadas por elas são distintas. Sguissardi (2006) ilustra essa distinção ao evidenciar um enfraquecimento do tripé ensino, pesquisa e extensão, no qual as universidades com sistemas de pós-graduação consolidados desenvolviam programas de pesquisa. $\mathrm{O}$ autor aponta para a expansão e predominância de outro modelo de ensino, denominado por ele de "universidade de ensino", no período de 1995 até 2006, em detrimento do modelo de "universidade de pesquisa". Tal situação fica explícita com a disseminação das IES privadas, em sua grande maioria, mais próximas do enquadramento como "universidade de ensino", o que novamente as afasta, na prática, da maioria das universidades públicas, mais próximas do entendimento de "universidade de pesquisa".

A falta de distinção formal entre esses contextos públicos e privados fica clara quando Cunha (2004) analisa a Lei de Diretrizes e Bases da Educação Nacional (LDB) e argumenta que a instituição universitária foi definida, de modo genérico, como aquela que desenvolve produção intelectual, que deve cumprir requisitos específicos, relativos à qualificação e dedicação do corpo docente, quais sejam, um terço deve ter títulos de mestre ou doutor e um terço deve atuar na instituição em tempo integral. Esta seria, segundo o autor, uma tentativa de indução de melhoria da qualidade para todas as IES que, entretanto, pode produzir efeitos diversos do idealizado, pois as IES públicas, de modo geral, têm demonstrado possuir melhores condições para poder cumprir tais exigências legais do que as privadas.

Esse aspecto em especial, o corpo-docente, é central na avaliação e na regulação das IES, sejam elas públicas ou privadas, uma vez que a sua composição repercute (positiva ou negativamente) no processo de ensino e aprendizagem, na formação dos alunos e na educação como um todo. Mas existem outros aspectos que também são avaliados, tais como: a coerência dos conteúdos curriculares com as Diretrizes Curriculares Nacionais; o Estágio Supervisionado; a disciplina de Libras; as condições de acesso para pessoas com necessidades especiais, inclusive com mobilidade reduzida; o Trabalho de Conclusão de Curso e o Núcleo Docente 
Estruturante (INEP, 2009). Tais aspectos servem de base para que o Ministério da Educação defina suas políticas regulamentadoras, em termos de avaliação, regulação e supervisão.

Considerando-se a articulação entre a avaliação e o processo regulatório dos cursos já existentes - uma vez que os resultados da avaliação interferem no reconhecimento e na renovação - verifica-se a relevância desses dois processos para as IES, tendo em vista que é com base nos resultados da avaliação dos cursos e das instituições, em análise conjunta com os demais eixos, que recebem o aval para a continuidade de suas atividades ou, o enforcement para o encerramento das mesmas.

O processo de regulação e de supervisão têm embasamento na avaliação realizada pelo SINAES e ambos os processos visam a promover a melhoria da qualidade da educação superior (INEP 2009). Em relação ao processo de supervisão, este se refere a uma espécie de inspeção das instituições, bem como de seus cursos, com o qual se procura verificar a conformidade entre o que determina a legislação e o que, de fato, está sendo praticado na educação superior. Ao verificar certa não conformidade, as penalidades previstas podem ir desde a desativação de cursos e habilitações até a modalidade de descredenciamento da própria instituição. A preocupação passa a ser, então, o que se considera como uma não conformidade.

Essa discussão envolve o tipo de política pública educacional que está sendo produzido no Brasil, que é permeado pela discussão de minúcias e definições legais tipicamente formalistas. Isso ocorre no país ao mesmo tempo em que o número de instituições aumenta consideravelmente, ampliando o alunado abrangido (CUNHA, 2004; INEP, 20011b), o que, obviamente, cria obstáculos para a operacionalização adequada de avaliações caracterizadas por essa tipologia.

Ao identificar esse formalismo (RIGGS, 1964; 1968) as IES tendem a responder por meio de um processo que pode ser compreendido a partir do que DiMaggio e Powell (1983) chamam de isomorfismo institucional. Ou seja, elas se adéquam às regras ou buscam parecer adequadas assemelhando-se às outras organizações, ao mesmo tempo em que mediam as pressões às quais estão submetidas. Essa preocupação, predominantemente institucional, tem implicações específicas na dinâmica das IES brasileiras, sobretudo as de natureza privadas que, de certa forma, submetem-se à lógica de mercado para se manterem, para prosperar, ou mesmo, para ter a sua sobrevivência comprometida. 


\section{0 isomorfismo institucional na dinâmica das IES brasileiras}

De maneira sintetizada a institucionalização resulta do processo de formação de hábitos. Em outros termos, quando há uma tipificação recíproca de ações habituais ocorre a institucionalização (BERGER; LUCKMANN, 2008). Um exemplo disso é o processo estabelecido pela regulamentação governamental imposta ao setor de educação superior brasileiro (SILVAJUNIOR; MUNIZ, 2004; SILVA JUNIOR, 2006). Nesse processo observa-se a presença do isomorfismo institucional (DIMAGGIO; POWELL, 1983), visto como um processo restritivo que força uma unidade numa população a parecer com outras que enfrentam o mesmo conjunto de condições ambientais.

No contexto da educação superior brasileira, o isomorfismo institucional leva as IES à condição de certa uniformidade institucional (isomórfica), por meio de três mecanismos: (1) o isomorfismo coercitivo, derivado de pressões formais e informais de instituições em condições de impor restrições às IES, (2) o isomorfismo mimético, baseado na imitação de outras IES e resultante de respostas às incertezas e (3) o isomorfismo normativo, decorrente das semelhanças entre os membros que atuam nas IES, em virtude de aspectos comuns em sua formação profissional.

O processo isomórfico impõe limites à natureza, modalidade e constituição das IES e a regulamentação faz parte dele. Quanto à natureza, as IES podem ser públicas ou privadas (com e sem finalidade lucrativa); quanto à modalidade, podem assumir a condição de universidade, centro universitário, centro federal de educação tecnológica, faculdades integradas, faculdades isoladas e institutos superiores de educação; e, quanto à constituição, as IES (públicas ou privadas) constituem-se como um sistema composto por dois subsistemas: mantenedora e mantida (INEP, 2009).

Foi a partir desse contexto isomórfico altamente regulamentado que Silva Junior e Muniz (2004) desenvolveram o Modelo Estrutural e Dinâmico da IES (Figura 2, a seguir), em que a entidade mantenedora, responsável pela estrutura de propriedade, se articula com a entidade mantida, responsável pela estrutura de direção. $\mathrm{Na}$ consecução de suas atividades, a entidade mantenedora, que goza de personalidade jurídica, é responsável por todas as questões administrativas (definição estratégica, contratação de funcionários e de serviços, outras), financeiras, jurídicas, contábeis, 
pedagógicas (criação e extinção de novos cursos, projetos pedagógicos, etc.) e estrutura física e manutenção, entre outros. Já a entidade mantida responsabilizase pelas questões de natureza eminentemente acadêmicas e prestação de serviços educacionais por meio de atividades de ensino, pesquisa e extensão, na oferta de cursos e programas em nível de graduação, pós-graduação, extensão e sequenciais, nas modalidades presencial, semipresencial e a distância.

Figura 2 - Modelo Estrutural e Dinâmico da IES

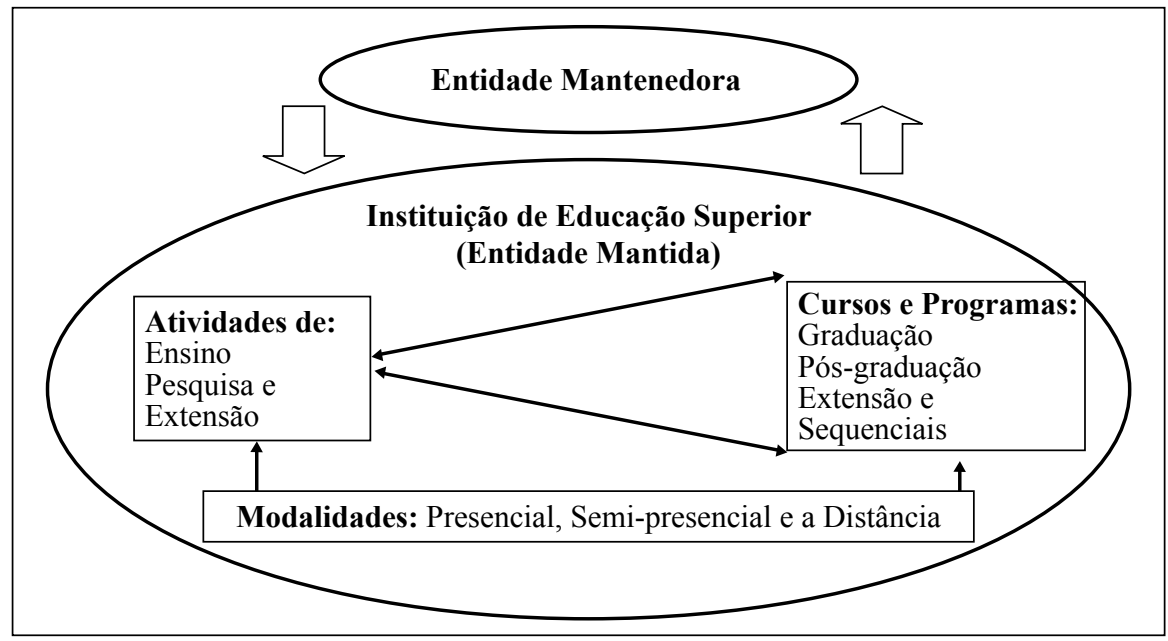

Fonte: SILVA JUNIOR; MUNIZ (2004, p. 8).

Nesse relacionamento que se estabelece entre entidade mantenedora e entidade mantida, há que se observar suas condições de dissociação, interdependência e autonomia. Dessa forma, para compreender a dinâmica institucional da IES no processo de gestão universitária (LAMARRA; BRÁ, 2004; COLOSSI, 2004), é possível identificar três níveis distintos de análises.

O primeiro nível é o da mantenedora, em que a dinâmica institucional e o processo de formação de estratégias são direcionados para os interesses de propriedade, como, por exemplo, resultados financeiros, questões patrimoniais e societárias, entre outras. O segundo nível é o da mantida, em que a dinâmica institucional e o processo de formação estratégica são direcionados para os interesses de natureza acadêmica, educacional e de gestão universitária, como, por exemplo, número de cursos ofertados, qualificação do corpo docente, avaliação 
institucional entre outros. O terceiro nível é o nível institucional integrado em que se analisa simultaneamente a entidade mantenedora e a entidade mantida em sua interdependência institucional.

A identificação desses três níveis de análise permite ao pesquisador fazer recortes metodológicos que viabilizam a análise acerca da gestão universitária que no primeiro nível, envolve exclusivamente demandas e interesses de propriedade, no segundo, demandas e interesses acadêmicos e, no terceiro, ambos. Ao articular esses três níveis é possível identificar como cada um deles interpreta as políticas públicas para a educação superior privada em termos da avaliação, da regulação e da supervisão do governo no sistema federal de educação superior. Ou seja, é um caminho que permite esclarecer como as IES lidam com a lógica formalística do sistema regulatório brasileiro.

4. O formalismo nas políticas públicas e nas práticas de gestão universitária Em obra intitulada "A Ecologia da Administração Pública", Fred Warren Riggs discute a questão do formalismo nas práticas de gestão. Segundo o autor o, formalismo consiste na discrepância entre a conduta concreta e a norma prescrita que se supõe regulá-la. É, em razão do formalismo, que o comportamento efetivo das pessoas desconsidera ou ignora as normas estabelecidas que a ele correspondem, sem que, com isso, estejam esses infratores sujeitos a sanções (RIGGS, 1964).

Do ponto de vista conceitual, esse formalismo apresenta-se como uma oposição ao realismo. Riggs $(1964,1968)$ observa que o formalismo corresponde ao grau de discrepância entre o prescritivo e o descritivo, entre o poder formal e o poder efetivo. Quanto maior a discrepância entre o formal e o efetivo, mais formalístico é o sistema.

Segundo o autor, esse fenômeno apresenta-se em todas as sociedades, sendo residual nas sociedades concentradas (aquelas dotadas de uma só estrutura com funcionalidade difusa) e nas sociedades difratadas (aquelas dotadas de diversas estruturas com funcionalidade específica), e dominante nas sociedades prismáticas (aquelas que representam o ponto médio entre esses dois tipos de sociedade). A sociedade brasileira é um exemplo de sociedade prismática, caracterizada pelo alto grau de heterogeneidade: nelas coexistem o velho e o novo, o antigo e o moderno, o atrasado e o avançado tecnologicamente, o rural e o urbano (RIGGS 1964; 1968; LAMBERT, 1967). 
Na visão de Riggs $(1964,1968)$, uma das raízes do formalismo está na adoção de modelos e conceitos tomados de uma ordem social mais refratada (presente nas sociedades difratadas, consideradas como mais evoluídas) pelas sociedades prismáticas (consideradas menos evoluídas e que, por isso, se referenciam na anterior para definir seus modelos). Mas em sua sociedade de origem esses modelos pressupõem a existência de uma estrutura formal, consolidada em termos de aspectos econômicos, administrativos e políticos que, na prática, ainda não foi desenvolvida na sociedade prismática, que, mesmo assim, absorve o modelo, culminando em pressões que geram a discrepância de conduta entre o efetivo e o formal.

A despeito de toda a discussão empreendida por Fred Warren Riggs sobre o formalismo esteja mais voltada para a lógica da administração pública, a sua sistemática parece adequada e pertinente à análise das IES brasileiras, sejam elas públicas ou privadas, visto que o isomorfismo institucional provocado pela regulamentação governamental acaba por tornar todas as IES com características próximas e semelhantes, sobretudo, em relação à submissão às políticas públicas voltadas para a avaliação, a regulação e a supervisão da educação superior.

Um exemplo do exposto anteriormente, de certa discrepância de conduta entre o efetivo e o formal, pode ser observado em relação ao ENADE. Conforme Polidori; Marinho-Araújo; Barreyro (2006), o ENADE pretende proporcionar uma reflexão nos cursos e nas instituições, na medida em que constitui um momento privilegiado de interlocução com os estudantes, no qual poderia estimular a análise de seus processos formativos. Contudo, esse momento privilegiado pode transformar-se em um processo instrumentalizado, no qual passam a ser realizados cursos pré-ENADE, com foco em obter resultados positivos apenas na prova em si, visando a uma promoção da imagem das IES por meio de resultados que não refletirão, necessariamente, no desenvolvimento do discente na IES.

A avaliação deveria ensejar uma prática avaliativa, um mecanismo que promovesse a discussão e a reflexão institucional, mas, quando se busca a mera adequação instrumentalizada ao modelo de avaliação, observa-se a lógica formalística (RIGGS, 1964,1968), com efeitos práticos limitados em termos do que é advogado pelas políticas públicas para a educação superior elaboradas pelo governo federal.

Neste artigo, ao evidenciar e discutir as articulações das Instituições de Educação Superior privadas em torno de três aspectos relacionados a essas políticas 
(avaliação, regulação e supervisão), essa lógica formalística é identificada, nos estudos de caso investigados e discutidos a seguir, como um processo isomórfico com implicações específicas na dinâmica dessas IES.

\section{Aspectos metodológicos do estudo}

A discussão empreendida nesse artigo fundamenta-se em um conjunto de dados coletados e analisados por meio da realização de estudos de casos de natureza qualitativa (YIN, 2005; TRIVIÑOS, 2008) em cinco diferentes Instituições de Educação Superior (IES) privadas ao longo de cinco anos de pesquisas. Os estudos de caso foram realizados no contexto de dois grupos de pesquisa vinculados a dois programas de pós-graduação em administração com pesquisadores em comum, sendo três desses estudos vinculados a uma tese de doutorado, e dois vinculados a duas dissertações de mestrado.

Embora cada uma das cinco pesquisas tivessem problemas de pesquisas e objetivos próprios, todas abordaram, pelo menos, dois temas em comum: (1) gestão universitária; e, (2) avaliação das políticas públicas do governo federal para a educação superior no Brasil, em termos da avaliação, supervisão e regulação. Nesse sentido, fizeram parte dos roteiros de entrevistas das cinco pesquisas dois blocos comuns, que permitiram explorar a análise acerca de como as IES pesquisadas avaliavam essas políticas públicas e os impactos na gestão universitária. Esse recorte metodológico adotado nessas cinco pesquisas permitiu uma análise conjunta de dados em meio a um estudo que pode ser caracterizado como multicasos (YIN, 2005; TRIVIÑOS, 2008).

A coleta de dados ocorreu entre os anos de 2006 e 2010 por meio de triangulação (JICK, 1979) ao articular as seguintes técnicas: (1) análise documental, mediante dados primários fornecidos pelas próprias instituições, como estatutos, regimentos internos, Plano de Desenvolvimento Institucional (PDI), entre outros, e dados secundários disponíveis na base de dados do MEC, do INEP, da SESu entre outros; (2) observação assistemática, de fatos, artefatos, eventos, entre outros aspectos vivenciados que, seguindo um roteiro prévio foram registrados em diário de campo; e, (3) entrevistas semiestruturadas realizadas junto a 43 sujeitos de pesquisa com atuação nas IES. Para preservar a identificação das IES pesquisadas, optou-se aqui por identificá-las na análise por um número de 1 a 5 . O quantitativo de entrevistas realizadas nas IES foi distribuído da seguinte maneira: (a) IES 1: 6 entrevistas; (b) IES 2: 8 entrevistas; (c) IES 3: 11 entrevistas; (d) IES 4: 10 entrevistas; e, (e) IES 5: 8 entrevistas. 
Para apresentação das falas dos sujeitos de pesquisa ao longo do texto, optouse por utilizar as iniciais EN (entrevistado) seguido de um número (de 1 a 11 - dependendo do número de entrevistados por IES) e seguido da identificação da IES (de 1 a 5). Assim, por exemplo, a identificação EN10 IES3 refere-se ao entrevistado 10 vinculado à IES 3.

De forma geral, as cinco IES pesquisadas são instituições privadas de pequeno, médio e grande portes, localizadas em quatro Estados Brasileiros nas Regiões Sudeste e Sul. Para definição do porte da IES optou-se pelo seguinte critério: (1) pequeno porte = comunidade acadêmica (discentes, docentes e pessoal técnico administrativo) constituída de até 1.000 pessoas; (2) médio porte $=$ comunidade acadêmica entre 1.001 e 5.000 pessoas; e (3) grande porte = comunidade acadêmica superior a 5.001 pessoas. As instituições investigadas possuem as seguintes características:

IES 1: faculdade isolada de pequeno porte localizada na região metropolitana de um Estado da Região Sudeste, cujo credenciamento junto ao MEC ocorreu em 2001. A mantenedora possui finalidade lucrativa.

IES 2: universidade de grande porte localizada na capital de um estado da Região Sudeste cujo credenciamento junto ao MEC ocorreu na década de 1970. A mantenedora não possui finalidade lucrativa.

IES 3: universidade de grande porte localizada na capital de um Estado da Região Sudeste cujo credenciamento junto ao MEC ocorreu na década de 1970. A mantenedora não possui finalidade lucrativa.

IES 4: faculdade isolada de pequeno porte localizada no interior de um Estado da Região Sudeste cujo credenciamento junto ao MEC ocorreu em 2000. A mantenedora não possui finalidade lucrativa.

IES 5: faculdade isolada de médio porte localizada numa região metropolitana da Região Sul cujo credenciamento junto ao MEC ocorreu em 2001. A mantenedora possui finalidade lucrativa.

Os dados coletados foram submetidos à análise temática de conteúdo (BARDIN, 2004; MINAYO, 2001) e agrupados em três macroeixos de categorias de uma grade aberta: (1) gestão universitária; (2) formalismo na educação superior; e, (3) políticas públicas. Por considerar a natureza sistêmica e de interdependência entre essas três categorias, estruturou-se a apresentação e a análise dos dados por meio de dois tópicos, conforme segue: gestão universitária nas IES pesquisadas e políticas públicas para a educação superior. 


\section{A gestão universitária nas IES pesquisadas}

Antes de abordar os aspectos relacionados à gestão universitária nas IES pesquisadas, cabe comentar que a diversidade de características das cinco instituições pesquisadas em termos da modalidade (faculdade isolada e universidade), da natureza (com e sem finalidade lucrativa), do porte (pequeno, médio e grande), da localização (quatro diferentes Estados das Regiões Sudeste e Sul), fase do ciclo de vida (crescimento e maturidade), entre outras, possibilitou analisar contextos institucionais distintos, identificando pontos de convergência e de divergência entre eles, o que enriqueceu a análise e discussão da temática abordada no artigo.

A partir dos dados coletados e analisados, buscou-se tratar as IES da maneira como defendem Lamarra e Brá (2004) e Colossi (2004): a gestão universitária concebida como a tarefa gerencial que conduz a instituição universitária, ou seja, uma unidade estrutural que se constrói conceitualmente por meio da identificação de diferentes planos de reflexões mutuamente vinculados, que têm como principais protagonistas os seus instituidores, proprietários e funcionários e suas relações sociais internas e externas, capazes de conduzir as instituições a resultados organizacionais em termos de desempenho, segundo múltiplos critérios avaliativos.

Nesse sentido, ao serem indagados acerca das atividades de gestão universitária em suas respectivas IES, os entrevistados comentaram fundamentalmente acerca de três tarefas centrais: o planejamento, a implementação e o controle, como se observa nos fragmentos de entrevistas a seguir.

01) (...) Antigamente nós tínhamos mais liberdade para planejar as nossas ações (...) mas, não era realizado de forma sistemática. Às vezes, o planejamento deixava mesmo de ser feito... (EN8 IES3).

02) A dinâmica do planejamento mudou com a instituição do PDI (...) A instituição é obrigada a elaborar e implementar o seu plano, pois será avaliado por isso quando das avaliações do MEC (EN4 IES2).

03) Para nós o PDI deve ser elaborado pela mantenedora, pois é ela quem faz os estudos estratégicos para verificar as demandas da região onde a mantida está inserida, é ela quem aloca os recursos necessários para os grandes projetos (...) Contudo, existe a efetiva participação da direção da mantida nesse processo decisório... (EN1 IES 4). 
Das falas é possível destacar alguns aspectos essenciais, quais sejam: (1) as mudanças na gestão universitária em razão da obrigatoriedade do PDI; (2) a interdependência e retroalimentação entre os processos de gestão universitária (planejamento, implementação e controle), decorrentes das ações de regulamentação governamental a partir do PDI e da avaliação; e, (3) a relação entre as entidades mantenedora e mantida no contexto da gestão universitária.

O primeiro aspecto está relacionado à liberdade gerencial exercida pelas IES mais antigas que, em épocas passadas, tinham no planejamento gerencial e estratégico uma atividade voluntária e não obrigatória, diferenciando-se do que é exigido hoje em termos da elaboração do PDI. Esse último aproxima-se da lógica formalística nos casos das instituições nos quais o planejamento não faz parte da prática institucional e é tratado como exigência burocrática. Esse processo pode ser mais bem compreendido ao se considerar o entendimento de Luckesi (1994) de que o planejamento é uma atividade humana intencional, ideologicamente comprometida que implica escolhas, ao projetar fins e estabelecer meios para atingi-los. Sem a referida intencionalidade e o referido comprometimento, aquilo que em uma lógica formalística se pode chamar de planejamento, na prática pode não configurar-se como tal, e nem mesmo precisa visar a ser atingido, pois basta atender à demanda burocrática que o seu papel terá sido cumprido.

Além disso, o reconhecimento das amarras ideológicas do planejamento exige admitir que as escolhas a ele relacionadas assentam-se em opções filosóficas e políticas, que possibilitam ao gestor e/ou planejador a liberdade de planejar intencionalmente ou de agir sem planejamento, o que não é uma opção dentro da lógica formalística.

Esse aspecto é mencionado no extrato 01 da fala do EN8 IES3, ao afirmar que os gestores poderiam ou não planejar suas ações gerenciais. Na época em que essa liberdade poderia ser exercida as IES assumiam os riscos de suas escolhas, em termos dos resultados que seriam produzidos. Após a obrigatoriedade do PDI, as instituições se viram condicionadas a planejar suas ações para atender à regulamentação, porém, esse planejamento em alguns casos assume caráter meramente formalístico (RIGGS, 1964, 1968), como se pode observar nas falas seguintes. identado

04) (...) o PDI era elaborado para atender ao MEC (...) Nós contratamos uma empresa de consultoria que nos orientou nesse sentido, definindo missão, visão, etc. (EN1 IES2). 
05) (...) [Apesar da existência do PDI] não existe planejamento estratégico na IES, (...) na prática conforme vão surgindo as necessidades é que se corre atrás para resolvê-las (EN2 IES5).

Desses fragmentos de entrevistas, pode-se identificar a presença de discrepância entre o que foi prescrito e o que, de fato, se efetivou, entre o "poder formal" e a prática efetiva. Aparentemente, o planejamento estratégico já institucionalizado (BERGER; LUCKMANN, 2008) em sociedades difratadas como a dos Estados Unidos da América, ainda eram incipientes no contexto gerencial brasileiro (sociedade prismática), fazendo com que o atrasado (prática gerencial intuitiva) se articulasse com o moderno (prática gerencial planejada sistematicamente), fazendo com que essa estrutura formal administrativa, na prática, não se materialize, culminando na discrepância de conduta entre o efetivo e o formal (RIGGS, 1964, 1968).

O segundo aspecto refere-se à interdependência e retroalimentação entre os processos de gestão universitária (planejamento, implementação e controle) que se materializam na dinâmica institucional impulsionados pela regulamentação governamental que exige a elaboração do PDI e submete às IES o processo de avaliação por meio do SINAES. De acordo com Luckesi (1994), planejamento e avaliação articulam-se de forma interdependentes, ao considerar que enquanto o planejamento dimensiona o que se vai construir, a avaliação auxilia essa construção, ao assumir condição de criticar o percurso dessa ação para fundamentar novas decisões. Em outros termos, o planejamento é o ato pelo qual se decide o que construir e, a avaliação é o ato crítico que auxilia no acompanhamento daquilo que está em construção. Nesse sentido, a avaliação atravessa o ato de planejar e de executar, por isso, contribui em todo percurso da ação planificada.

Aparentemente, foi seguindo essa lógica relacional proposta por Luckesi (1994) que o SINAES foi concebido. Ao se articular com a obrigatoriedade do PDI, o sistema avaliativo do SINAES tem como ponto de partida o planejamento estratégico realizado pelas IES em seu PDI, para avaliar os resultados produzidos pelas instituições e, com isso, desenvolver políticas públicas com as finalidades de alcançar melhorias na qualidade da educação superior; orientar a expansão da oferta de IES, de cursos e de vagas, entre outras (INEP, 2009). Desta forma, a regulamentação governamental utiliza o planejamento realizado, no âmbito da gestão universitária, pelas IES para 
avaliá-las, segundo critérios preestabelecidos pelas próprias instituições e pelo SINAES e, com isso, obter legitimidade para exercer enforcement para implementação de políticas públicas para a educação superior, inclusive as que podem punir as IES com a redução do número de vagas, com a suspensão de atividades educacionais e, até mesmo com o descredenciamento.

O terceiro aspecto enfoca a relação entre as entidades mantenedora e mantida no contexto da gestão universitária, em termos do nível institucional integrado de análise proposto por Silva Junior e Muniz (2004). Embora haja o discurso de autonomia da entidade mantida em relação à entidade mantenedora, o que se observa na prática é uma relação de interdependência, em que a autonomia não pode ser exercida plenamente por ambas, sem que uma não interfira na autonomia da outra. As falas seguintes ilustram essa questão.

06) (...) como tem uma exigência do MEC para a distinção entre mantenedora e mantida, nós decidimos utilizar a Escolinha [que já existia] como mantenedora e criar a Faculdade, que é a mantida (...) Nós somos em três sócios, eu, o meu irmão e o nosso pai. Como o nosso pai já possui uma certa idade, nós decidimos dividir as atribuições entre eu e o meu irmão (...) Como eu já tomava conta da administração da escolinha, passei a assumir a direção acadêmica da Faculdade, e o meu irmão ficou responsável pela mantenedora (EN1 IES1).

07) (...) alguns planos são propostos pelos colegiados de cursos, sendo a maioria proveniente diretamente da mantenedora. (...) esses planos são da IES como um todo (...) não existe um planejamento exclusivo de um curso, de forma isolada (...) no passado houve uma tentativa nesse sentido, mas que não foi efetivada na prática (EN3 IES5).

Observa-se na fala 07 do entrevistado "EN3 IES5" que a gestão universitária possui características sistêmicas, uma vez que contempla, simultaneamente, aspectos relacionados à gestão da mantenedora e à gestão da mantida. Com isso, os interesses administrativos, econômicos e financeiros da primeira se articulam com os interesses acadêmicos da segunda para conceber planos multifacetados que contemplem a IES como um todo. Assim, a dinâmica gerencial contempla a IES em todas as suas dimensões e estruturas, desde a mantenedora até a mantida nos aspectos institucionais, administrativos, jurídicos, de cursos, de ensino, de pesquisa e de extensão, entre outras. 
Em razão disso, acredita-se que a contribuição de Silva Junior e Muniz (2004) ao identificar três níveis distintos de análises das IES e da gestão universitária seja efetivo em termos acadêmicos e científicos, porém, essa efetividade é questionável em termos de políticas públicas para a educação superior. Esse e outros aspectos serão discutidos e detalhados mais adiante no tópico seguinte.

\section{As políticas públicas para educação superior: a avaliação, a regulação e a supervisão em debate}

Tendo como fundamento aspectos relativos à gestão universitária das IES pesquisadas buscou-se analisar a regulamentação governamental e as políticas públicas para educação superior em termos da avaliação, da regulação e da supervisão (INEP, 2009).

As falas seguintes representam a visão dos gestores entrevistados sobre essas políticas públicas:

08) (...) As ações do MEC são sempre voltadas para a mantida (...) PDI, PPC [Projeto Pedagógico de Curso], CPA [Comissão Própria de Avaliação], SINAES, CPC [Conceito Preliminar de Curso], ENADE são todas ações destinada à mantida (EN7 IES2).

09) Seguramente, um dos aspectos de maior impacto para a imagem da instituição junto ao mercado é o ENADE (...) A nota no ENADE é um instrumento importante para divulgação da instituição... (EN8 IES3).

010) (...) para o ENADE 2009, algumas táticas foram utilizadas para divulgar sua importância (...) os docentes foram solicitados a discutir esse assunto em sala de aula (...) conforme a IES foi avaliando a nota do ENADE dos cursos, alguns projetos que não estavam sendo priorizados foram alavancados (...) o ENADE foi o argumento para que levassem algumas questões mais a sério (...) foi necessário adequar o estilo da prova adotado pelos professores ao estilo de questões adotado pelo $\operatorname{ENADE~(...)~foi~uma~}$ forma encontrada para ir treinando o aluno para o ENADE (EN5 IES5).

Pode-se observar nas falas dos entrevistados como as políticas públicas para a educação superior têm sido tratadas pelo MEC e como são apreendidas pelas IES. Uma das questões refere-se ao direcionamento dessas políticas públicas quase que exclusivamente para a entidade mantida, desconsiderando a relevância da mantenedora nesse contexto. 
Tendo como referência o Modelo Estrutural e Dinâmico de IES (SILVA JUNIOR; MUNIZ, 2004), observa-se que direcionar políticas públicas apenas para o subsistema mantida do sistema IES, pode ser considerada como um equívoco por parte do MEC. A entidade mantenedora, por possuir personalidade jurídica e assegurar a mantença do centro acadêmico mantido, deveria ter por parte do MEC maior supervisão quanto à atuação dessas entidades, sobretudo em relação às políticas financeiras internas da mantenedora quanto a destinação dos recursos. Não se pode ignorar, por exemplo, a natureza jurídica da mantenedora quanto à sua finalidade lucrativa ou não. Dependendo da modalidade, essas entidades assumem regime jurídico e tributário que impõem limites quanto à destinação de recursos financeiros. Por exemplo, as entidades sem finalidade lucrativa, para gozar de imunidade tributária e fiscal não podem remunerar seus sócios instituidores e devem reinvestir todo resultado financeiro na própria atividade fim da IES ${ }^{1}$.

Sem a articulação entre os aspectos jurídicos e financeiros da mantenedora e os acadêmicos da mantida, a dinâmica institucional da IES fica comprometida, assim como os resultados decorrentes dessa dinâmica. Considerando a predominância das IES privadas em comparação com as públicas na educação superior brasileira (INEP, 2011a; 2011b), essa questão merece maior atenção no contexto da regulamentação governamental, sobretudo em um contexto de "mercantilização" da educação superior (NUNES, 2007).

Observa-se ainda na fala 08 a criação de um dialeto próprio instituído pelo MEC para a educação superior e, em especial, para a atuação das IES. Cada uma dessas siglas está de alguma forma relacionada à avaliação, à regulação e à supervisão da atuação da IES em termos da operacionalização das políticas públicas para a educação superior (INEP, 2009).

No que tange à avaliação, constata-se que dos três eixos defendidos por Polidori, Marinho-Araújo e Barreyro (2006), o terceiro, que se propõe a avaliar o desempenho dos alunos via ENADE, é considerado como o mais relevante para a relação da IES com o mercado como um todo.

A fala 10 demonstra que, para a IES, a lógica do processo de avaliação tem uma conotação maior de fiscalização e adequação aos padrões de qualidade

1 Para maiores informações consultar a Instrução Normativa SRF n 113, de 21 de setembro de 1998 no site http://www.receita.fazenda.gov.br/legislacao/ins/ant2001/1998/in11398.htm 
estabelecidos pela nota atribuída à IES do que de preocupação com o aprimoramento da educação como um todo, em seu tripé ensino, pesquisa e extensão. Em linhas gerais, percebe-se que o receio das instituições com o resultado dessa fiscalização está na identificação de uma possível não conformidade, que possa culminar em penalidades como a desativação de cursos e o descredenciamento da própria instituição. Aparentemente, as estratégias utilizadas têm como foco o treinamento de docentes e discentes sobre como lidar com o exame e, não com o processo ensino e aprendizagem que está sendo praticado pela IES. Nesse sentido, a dinâmica praticada pelas IES, assume uma lógica formalística (RIGGS, 1964, 1968), cujo objetivo é alcançar uma nota que expresse uma qualidade a ser divulgada para o mercado e não com a qualidade em si.

Embora haja o reconhecimento por parte do MEC e das próprias IES, de que, para alcançar a qualidade na educação superior, é necessária uma articulação mais ampla, envolvendo múltiplas dimensões, como, por exemplo, o PDI, o PPC, a organização didático e pedagógica dos cursos, a atuação do corpo docente (qualificação, dedicação, envolvimento em atividades de ensino, pesquisa e extensão, produção científica), e, a capacidade instalada da IES; na prática, o que se observa é uma gestão universitária doutrinada para atender meramente os critérios avaliativos e de qualidade definidos pelo MEC, numa lógica de conformidades e não conformidades típicas dos tradicionais programas de qualidades em gestão, como os instituídos pelo Prêmio Nacional de Qualidade (PNQ), seguido por várias organizações brasileiras.

O dilema aqui envolve as relações de interesse e a assimetria de informação entre as partes envolvidas. Por exemplo, nas empresas, em geral, comumente, os clientes possuem experiências e informações adicionais para julgar os efeitos práticos do PNQ nos produtos e serviços da empresa, mas, nas IES, os indicadores se colocam como tendo um fim em si mesmo para os futuros alunos. Isso ocorre, pois a comparação na prática só é possível após a inserção do aluno na instituição, comumente sem uma referência de comparação com outras instituições de ensino. Tal assimetria de informação e o fato de que os prejuízos por encerrar a relação com as IES gera implicações pessoais profundas para o cidadão brasileiro em toda sua trajetória profissional, faz com que o poder público tenha que assumir a responsabilidade de mediar essa relação, indo além do formalismo típico das instâncias e agências regulamentadoras do Estado brasileiro. 
Essa crítica à lógica formalística do Estado no setor educacional não implica que o poder público deva afastar-se do seu papel regulamentador, muito pelo contrário. Nesse caso, além de se tratar de algo ofertado à sociedade brasileira, de interesse público e como uma concessão pública, essa relação envolve partes com um nítido desequilíbrio em termos das possibilidades de mediarem as relações de interesses envolvidas, portanto, é papel do Estado intervir diretamente nesse contexto.

A preocupação aqui é que, comumente, essa intervenção tem sido permeada por uma lógica formalística limitada. Em outros setores essa lógica se sustenta por ser complementada por meio da regulação pelo próprio mercado, mas isso não se aplica adequadamente no caso do setor educacional. A concorrência existente nesse setor é intensa, mas não é capaz de sanar a mencionada assimetria e o desequilíbrio entre as partes em virtude das características descritas, portanto, cabe ao Estado brasileiro ir além da lógica formalística típica, em um esforço para romper sua tradição secular, pelo menos ao tratar com o setor de educação. As minúcias burocráticas não devem ser simplesmente abandonadas, mas o seu lugar é o segundo plano, pois os efeitos práticos no cotidiano das IES deveriam estar em primeiro plano, bem como o debate sobre os interesses financeiros e tributários das mantenedoras que só se refletem no rebatimento prático, mas que têm implicações profundas nos investimentos no processo didático-pedagógico de ensino e aprendizagem.

\section{Considerações finais}

Seguindo a orientação de políticas públicas neoliberais, a educação superior no Brasil passou por um processo de ampliação do número de IES e vagas ofertadas na esfera privada, identificada por alguns autores como Nunes (2007) de "mercantilização". A discussão realizada neste artigo se legitima nesse contexto, pois se preocupa com as políticas públicas voltadas para regulamentar esse processo.

Os resultados do confronto teórico e empírico realizado, indicam a necessidade de se repensar o assunto sobre as políticas públicas para a educação superior. Esse repensar das políticas públicas tem como ponto de partida o reconhecimento, por parte das IES pesquisadas, de que a "privatização" e a "mercantilização" foram fatores determinantes para a necessidade de ampla regulamentação do setor, como forma de controle do poder público junto ao Sistema Federal de Educação, hoje, predominantemente, privado.

2 Entendido aqui como o processo de ampliação do setor privado e redução do setor público. Não deve ser confundido com o sentido econômico (processo de venda de ativos públicos para a iniciativa privada). 
Porém, essa regulamentação, da maneira como se estabeleceu, tem produzido efeitos negativos para a educação superior, principalmente as múltiplas formas de interferência na gestão universitária das IES. Como, por exemplo, a obrigatoriedade do Plano de Desenvolvimento Institucional (PDI), sem, contudo, avaliar a sua efetividade prática ou se as IES têm condições para construir e realizar um PDI com coerência. Com isso, constata-se que a dinâmica gerencial das IES, em relação às políticas públicas, assume uma lógica formalística (RIGGS, 1964, 1968) em que o processo de avaliação, supervisão e regulação tem como fundamento atender ao que prescreve a norma e não ao que, de fato, é relevante: a qualidade da educação superior e o desenvolvimento do discente.

Com isso, verifica-se, por parte das IES, uma acomodação e, até mesmo, uma doutrinação formalística ao submeter-se a essa regulamentação, sofrendo, mesmo que parcialmente, interferências em sua autonomia gerencial para cumprir com a norma imposta, mas sem que se veja ameaçada em termos de promover mudanças mais profundas com efetivas implicações práticas. Dessa maneira, a despeito das IES poderem manifestar-se contra o processo burocrático que envolve as políticas públicas no seu setor, é cômodo para elas aceitar o processo, uma vez que não envolve mudanças profundas, complexas e delicadas com rebatimentos práticos em seu cotidiano, o que poderia exigir dos seus gestores e proprietários maneiras completamente distintas de atuar e talvez até novos gestores e proprietários.

Acredita-se que a mudança desta realidade passe pela necessidade de mobilização da sociedade para questionar esse modelo de regulamentação para que a causa educacional em termos da qualidade dos serviços prestados pelas IES públicas e privadas seja efetiva e não meramente um discurso formalístico. Nessa direção, após expor a lógica formalística como o principal empecilho para essas mudanças, este artigo propõe como contribuição final a realização de discussões adicionais, a partir daqui, sobre como operacionalizar a superação dessa lógica formalística. Uma alternativa, por exemplo, talvez seja uma maior presença in loco dos representantes do Estado, não somente para assumir os papéis de avaliadores, reguladores e supervisores, mas, principalmente, atuando como educadores preocupados em compreender o contexto em que o processo educacional se desenrola em suas múltiplas dimensões, para, a partir dessa compreensão, atuar em conjunto com as IES no desenvolvimento de alternativas efetivas para a melhoria da qualidade dos serviços educacionais prestados. É recomendável que essa presença do Estado ocorra de forma espontânea e não programada; sem data e hora marcadas; nem longos períodos cíclicos de vários anos para sua realização; que se 
materialize com a participação dos discentes e docentes que vivenciam o cotidiano, pelo menos até que a sociedade brasileira tenha uma estrutura formal amadurecida, em termos de aspectos econômicos, administrativos e políticos no qual o formal e a prática se aproximam na instância institucional. Mas esse caminho, como diversos outros possíveis, têm muitas implicações a ser discutidas em outros estudos.

\section{Referências}

BARDIN, L. Análise de conteúdo. 3. ed. Lisboa: Edições 70, 2004.

BERGER, P. L.; LUCKMANN, T. A construção social da realidade. Rio de Janeiro: Vozes, 2008.

BRASIL. Decreto $\mathrm{n}^{\circ}$ 6.317, de 20 de dezembro de 2007. Aprova a Estrutura Regimental e o Quadro Demonstrativo dos Cargos em Comissão e das Funções Gratificadas do Instituto Nacional de Estudos e Pesquisas Educacionais Anísio Teixeira - INEP, e dá outras providências. Diário Oficial [da] República Federativa do Brasil, Brasília, DF, p. 9, 21 dez. 2007a.

. Decreto n. ${ }^{\circ}$ 6.320, de 20 de dezembro de 2007. Aprova a Estrutura Regimental e o Quadro Demonstrativo dos Cargos em Comissão e das Funções Gratificadas do Ministério da Educação, e dá outras providências. Diário Oficial [da] República Federativa do Brasil, Brasília, DF, p. 16, 21 dez. 2007 b.

COLOSSI, N. A dicotomia crise mudança no comportamento de instituições de ensino superior. In: COLOSSI, N.; SOUZA PINTO, M. D. (Org.). Estudos e perspectivas em gestão universitária. Blumenau: Nova Letra, 2004. p. 21-34.

CUNHA, L. A. O público e o privado na educação superior brasileira: fronteira em desenvolvimento? In: TRINDADE, H. (Org.). Universidade em ruinas: na república dos professores. 3. ed. Petrópolis, RJ: Vozes, 1999. p. 39-56.

. Desenvolvimento desigual e combinado no ensino superior: Estado e mercado. Educação e Sociedade, Campinas, v. 25, n. 88, p. 795-817, Especial - Out. 2004.

DIMAGGIO, P.; POWELL, W. The iron cage revised: institutional isomorphism and collective rationality in organizational fields. American Sociological Review, [S.1.], v. 48, p. 147-160, 1983. 
DOMINGUES, I. Paradigmas e modelos das ciências humanas no século XX: as vias de Émile Durkhein e Max Weber. 2002. Tese (Professor Titular) - Faculdade de Filosofia e Ciências Humanas, Universidade Federal de Minas Gerais, Belo Horizonte, 2002.

INEP. Instituto Nacional de Estudos e Pesquisa Educacionais Anísio Teixeira. SINAES: Sistema Nacional de Avaliação da Educação Superior: da concepção à regulamentação. 5. ed. revisada e ampliada. Brasília: INEP, 2009.

. Censo da Educação Superior 2000. Disponível em <http://www.inep. gov.br/superior/censosuperior/sinopse/default.asp >. Acesso em: 4 mar. 2011a.

. Censo da Educação Superior 2009. Disponível em <http://www.inep. gov.br/superior/censosuperior/sinopse/default.asp >. Acesso em: 4 mar. 2011b.

JICK, T. D. Mixing quantitative and qualitative methods: triangulation and action. Administrative Science Quarterly, [S.1.], n. 24, p. 602-611, 1979.

LAMARRA, N. F.; BRÁ, M. A. La gestión universitaria en la Argentina: una aproximación a partir de la evaluación institucional externa. In: COLOSSI, N.; SOUZA PINTO, M. D. (Org.). Estudos e perspectivas em gestão universitária. Blumenau: Nova Letra, 2004. p. 21-34.

LAMBERT, J. Os dois Brasis. 2. ed. São Paulo: Nacional, 1967.

LUCKESI, C. C. Avaliação da aprendizagem escolar. São Paulo: Cortez, 1994.

MINAYO, M. C. S. (Org.). Pesquisa social. 18. ed. Petrópolis: Vozes, 2001.

NUNES, E. Desafio estratégico da política pública: o ensino superior brasileiro. Revista de Administração Pública, Rio de Janeiro, Edição comemorativa, p. 103-147, 2007.

POLIDORI, M. M.; MARINHO-ARAUJO, C. M.; BARREYRO, G. B. SINAES: Perspectivas e desafios na avaliação da educação superior brasileira. Ensaio: Avaliação e Políticas Públicas em Educação, Rio de Janeiro, v. 14, n. 53, p. 425-436, out./dez. 2006. 
RIGGS, F. W. A ecologia da administração pública. Rio de Janeiro: Fundação Getúlio Vargas, 1964.

. Administração nos países em desenvolvimento: a teoria das sociedades prismáticas. Rio de Janeiro: Fundação Getúlio Vargas, 1968.

SGUISSARDI, W. Reforma universitária no Brasil -1995-2006: precária trajetória e incerto futuro. Educação e Sociedade, Campinas, v. 27, n. 96, p. 1021-1056. Especial, out. 2006.

SILVA JUNIOR, A. da; MUNIZ, R. M. A Regulamentação do ensino superior e os impactos na gestão universitária. In: COLÓQUIO INTERNACIONAL SOBRE GESTÃO UNIVERSITÁRIA DAAMÉRICA LATINA, 4., 2004, Florianópolis. Anais... Florianópolis: 2004.

SILVA JUNIOR, A da. Trajetória de crescimento, governança corporativa e gestão universitária: estudo de caso em três instituições de educação superior do tipo familiar. Tese (Doutorado)-Centro de Pós-Graduação e Pesquisa em Administração da Faculdade de Ciências Econômicas da Universidade Federal de Minas Gerais. Belo Horizonte: UFMG, 2006, 384p.

TRIVIÑOS, A. N. S. Introdução à pesquisa em ciências sociais: a pesquisa qualitativa em educação. 16. ed. São Paulo: Atlas, 2008.

YIN, R. K. Estudo de caso: planejamento e métodos. 3. ed. Porto Alegre: Bookman, 2005.

Recebido em: 08/07/2011

Aceito para publicação em: 31/03/2013 


\section{Public policies for higher education: the evaluation, the regulation and the supervision of the private HES in debate Abstract}

This paper aims to highlight and discuss the private Higher Education School (HES) articulation around three aspects related to public policies for higher education: evaluation, regulation and supervision. The discussion is based on data collected and analyzed through five case studies. The results indicate the need to rethink public policies, especially in terms of the practical effects of government regulation on the HES and the definition of roles and functions of evaluation, regulation and supervision. These public policies interfere on the university management without evaluating their practical effectiveness. It makes the dynamics between HES and public policy take a formalistic logic, which causes damage to higher education and society.

Keywords: University Management. Public Policies. Higher Education.

\section{Las políticas públicas de educación superior: la evaluación, la regulación y la supervisión de IES privadas en debate}

\section{Resumen}

El objetivo de este trabajo es destacar y discutir las articulaciones de las Instituciones de Educación Superior (IES) privadas analizando tres aspectos de las políticas públicas en ellas, a seguir: evaluación, regulación y supervisión. La discusión se basa en datos recogidos y analizados por cinco estudios de caso. Los resultados señalan la necesidad de repensar las políticas públicas, especialmente en términos de los efectos prácticos de la regulación gubernamental en las IES y las definiciones del rol y las funciones de estos tres aspectos. Estas políticas públicas interfieren en la gestión universitaria, sin, en verdad, evaluar su eficacia práctica, por lo que la dinámica entre las IES y las políticas públicas tiene una lógica meramente formalística que le hace daño a la educación superior y a la sociedad.

Palabras clave: Gestión Universitaria. Políticas Públicas. Educación Superior. 